\title{
TRAUMATIC LESIONS OF THE OPTIC CHIASMA*†
}

\author{
BY \\ W. C. LOGAN AND D. S. GORDON \\ From the Departments of Ophthalmology and Neurosurgery, Royal Victoria Hospital, Belfast
}

LESIONS of the optic chiasma are rarely associated with head injury. Examination of the chiasma at operation or autopsy has been reported on very few occasions. Traquair, Dott, and Russell (1935) found only 27 cases in the literature and added three of their own.

More recently, in a series of ninety cases of indirect injury to the optic nerve and chiasma combined, Hughes (1962) included seven cases of injury to the optic chiasma alone. Loss of optic nerve function following indirect injury is usually attributed to ischaemia (Traquair, 1942; Turner, 1943; and Symonds, 1945). There is less agreement about the mechanism in all traumatic chiasmal lesions.

In autopsy studies, Liebrecht (1906) described traumatic division of the chiasma and Körber (1889) found partial division in a patient who died immediately after the injury. In less severe injuries, Østerberg (1938) was able to demonstrate small lesions in the chiasma which he attributed to the direct stretching or contusion of the chiasma rather than damage to the local blood supply.

Duke-Elder (1939) concluded that traumatic chiasmal lesions usually resulted from ischaemia. Symonds (1945) reported four patients with total chiasmal lesions, who all had severe anterior fossa fractures from frontal injuries; he thought that transient skull distortion could cause ischaemia of the chiasma.

When bitemporal hemianopia followed injury to the vertex of the skull, Rand (1936) suggested that the chiasma might suffer contre-coup damage. He emphasized, however, that chiasmal lesions usually result from frontal and facial injuries in which the optic foramina may be separated, and he pointed out that the optic chiasmal fibres, being weaker than the optic nerve, would tend to tear first.

In an exploratory operation on a patient with a complete bitemporal hemianopia due to trauma, Hughes (1945) could find no macroscopic pathology. He later concluded (Hughes, 1962) that distortion of the skull with or without fracture could separate the optic canals and tear the centre of the chiasma, but that in many cases the damage was due to interference with the blood supply to the central vessels of the sagittal area of the chiasma.

The following case report concerns a patient with a traumatic optic chiasmal lesion in which the opportunity arose to inspect the chiasma at operation. The findings suggest that the chiasmal damage resulted from stretching.

* Received for publication November 12, 1965.

$\dagger$ Address for reprints: Royal Victoria Hospital, Grosvenor Road, Belfast, N. Ireland 


\section{Case Report}

A 33-year-old man sustained frontal and facial injuries in a road accident on December 19, 1963, and was admitted to the Department of Neurological Surgery, Royal Victoria Hospital, Belfast.

He was not deeply unconscious but remained drowsy and irritable for 2 weeks. There were multiple bilateral frontal fractures which extended into the anterior fossa and involved the ethmoidal and sphenoidal air sinuses. Both malar bones were fractured with backward displacement causing a "dish face" appearance.

Examination.-On the 18th day after injury it was possible to assess the visual acuity: 6/9 in the right eye and counting fingers in the left.

The left pupil was slightly larger than the right and reacted very slightly to direct light and only a little better to consensual light stimulation. The right pupil reacted briskly to direct light and moderately well to consensual stimulation.

The right ocular movements were normal, but those on the left were severely limited, except lateral movement which was normal.

In the right fundus there was a superficial haemorrhage in the retina near the nasal side of the disc. The left fundus showed slight pallor of the optic disc but was otherwise normal.

Visual Fields (Figure).-The right showed gross loss of the temporal half but the central area up to $10^{\circ}$ from the fixation point was spared. The left showed complete loss of the temporal half and partial loss of the central part of the nasal half.

Although the field loss was quite asymmetrical, the sharply-demarcated hemianopia suggested some damage to the chiasma with probable further damage to the left optic nerve. This preferential injury of one nerve as well as the chiasma is said to occur in 30 per cent. of cases (DukeElder, 1949).

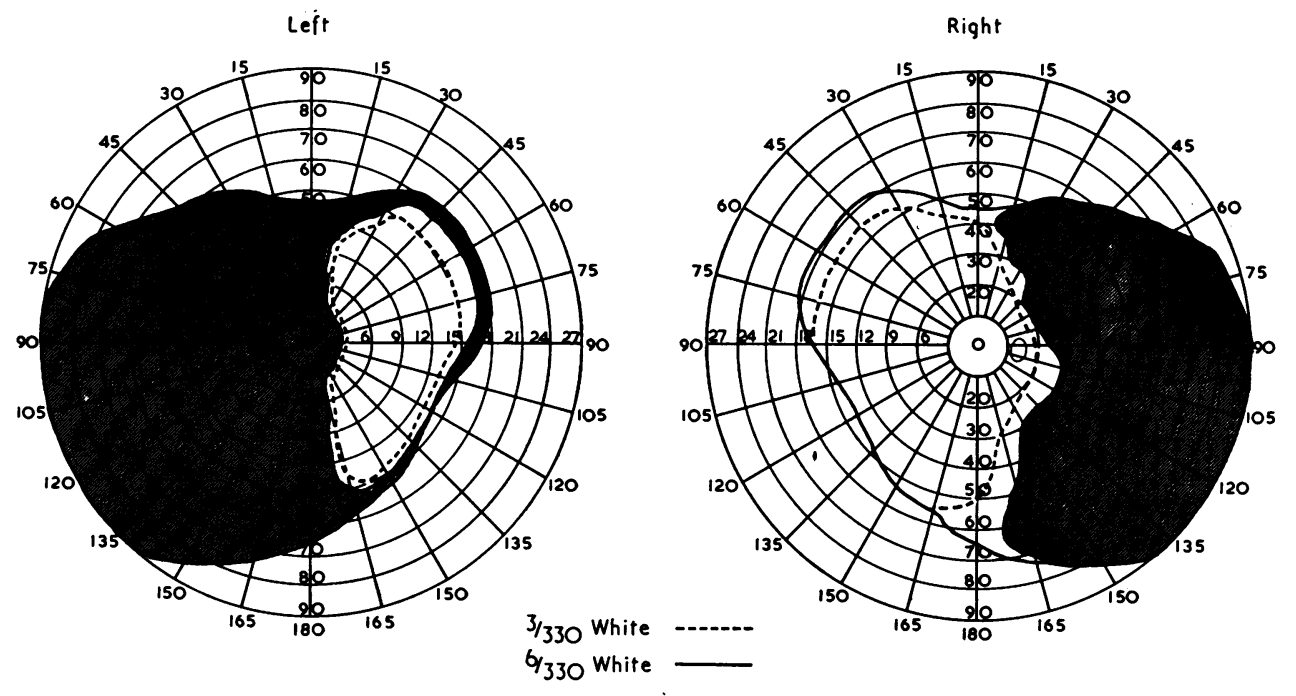

Figure.-Visual fields in a case of trauma to the optic chiasma.

Progress.-The patient's general condition improved, but one month after injury he developed a cerebrospinal fluid rhinorrhoea and a large aerocele of the right frontal lobe.

Operation.-An anterior fossa dural repair was carried out by Mr. D. S. Gordon, in the course of which the ethmoidal sinus area was exposed. This part of the skull was fractured and displaced backwards. The left optic nerve was stretched and kinked laterally round the displaced tuberculum sellae with resultant stretching of the optic chiasma.

There was no local haematoma formation and no macroscopic evidence of optic chiasmal damage. 
Result.-Post-operative recovery was uneventful, and the patient has returned to work but there has been no improvement in the visual fields. He has bilateral anosmia but no other neurological signs, and in particular no evidence of impairment of pituitary function.

\section{Discussion}

The optic chiasma usually lies more than $1 \mathrm{~cm}$. above and behind the optic groove on the sphenoid bone. Even the pre-fixed optic chiasma is at least $0.5 \mathrm{~cm}$. away from the bone. This led Traquair and others (1935) to conclude that the division of the chiasma by skull fracture is unlikely, and they found no evidence of bone displacement in this area in the series of thirty cases which they reviewed. In patients with severe anterior fossa fractures, however, the base of the skull probably undergoes considerable distortion.

Transient lateral displacement of one or both optic foramina could cause shearing of the chiasma. In the patient here reported, the optic nerve damage resulted from sudden distortion and displacement and it appeared almost certain that stretching had caused the chiasmal lesion.

Ischaemia may be a factor in causing chiasmal damage in some cases, but an exclusive blood supply to the chiasma has not been demonstrated. François, Neetens, and Collette (1958) concluded:

"It is inconceivable that the chiasma, which is profusely supplied by eleven arteries and a whole network of anastomotic arterioles, should be functionally impaired by the occlusion of one or even more arteries. The functional defects should be attributed to intra-tissular capillary affection due either to degeneration or more frequently to compression from outside".

\section{Summary}

A case of bitemporal hemianopia due to traumatic damage to the optic chiasma is reported in which an opportunity arose to inspect the chiasma at operation. The findings suggest that in this case damage was due to stretching. The mechanism of damage in this type of injury is discussed and the literature briefly reviewed.

\section{REFERENCES}

DUKe-Elder, S. (1949). “Text-book of Ophthalmology”, vol. 4, p. 3559. Kimpton, London.

François, J., Neetens, A., and Collette, J. M. (1958). Brit. J. Ophthal., 42, 65.

Hughes, E. B. C. (1945). Ibid., 29, 629. (1962). Bull. Johns Hopk. Hosp., 111, 98.

KÖRBER, B. (1889). Disch. Z. Chir., 29, 545.

Liebrecht (1906). Arch. Augenheilk., 55, 36.

ØSTERBERG, G. (1938). Acta ophthal. (Kbh.), 16, 466.

RAND, C. W. (1936). Arch. Surg., 32, 945.

SYMONDS, C. P. (1945). Trans. ophthal. Soc. U.K., 65, 3.

Traquair, H. M. (1942). An Introduction to "Clinical Perimetry", 4th ed., p. 203. Kimpton, London. - DotT, N. M., and Russell, W. R. (1935). Brain, 58, 398.

TURNER, J. W. A. (1943). Ibid., 66, 140. 